\title{
Burner Characteristics for Activated Carbon Production
}

\author{
Supaat zakaria ${ }^{1, a}$, A.M. Leman ${ }^{1}$, Dafit Feriyanto ${ }^{1}$,Azmarini A. Nazri ${ }^{2}$, N.M. Sunar ${ }^{1}$ and Mohd Najib Mohd Salleh ${ }^{3}$ \\ ${ }^{1}$ Faculty of Engineering Technology, Universiti Tun Hussein Onn Malaysia (UTHM) 86400, Parit Raja, Batu Pahat, Johor, Malaysia \\ ${ }^{2}$ Department of Mechanical Engineering, Politeknik Ungku Omar, Jalan Raja Musa Mahadi, 31400 Ipoh, Perak, Malaysia \\ ${ }^{3}$ Faculty of Computer Science and Information Technology, Universiti Tun Hussein Onn Malaysia 86400, Batu Pahat,Johor, Malaysia
}

\begin{abstract}
Carbonization process has become an important stage in developing activated carbon. However, existing burner are not efficient in time production which take 24 hours to15 days for charcoal production. Therefore, new design of burner/kilns is quite needed in order to produce larger number of charcoal in short time production, to improve charcoal quality regarding to the smooth surface area and pore volume. This research proposed new design burner which divided into two types which are vertical and horizontal types. Vertical is not completed by autorotating system while horizontal type is complete by auto-rotating and fume handling system. It developed using several equipment such as welding, oxy-cutting, drilling grinding and cutting machine. From the result of carbonization process shows that coconut shell charcoal need shorter time of 30 minutes as compared to palm shell charcoal of $2 \mathrm{~h}$ to completely carbonized. This result claim that the new design better than existing kiln that need longer time up to $24 \mathrm{~h}$. The result of the palm and coconut shell charcoal believe will produce better properties of activated carbon in large surface area and higher total volume of pores. Therefore, this burner is high recommended for producing palm and coconut shell charcoal as well as other bio-based material.
\end{abstract}

\section{Introduction}

Activated carbon (AC) is the carbon which activated using several methods like physical and chemical activation. There are many sources for AC development such as palm shell, coconut shell, woods, fish bones and bamboo. Prior to developing AC, raw materials need to be charcoaled and commonly called as carbonization process. Producing AC was conducted using several equipment such as using burner, drum kiln or conventional burning process. In the carbonization process, medium to high temperature has been investigated by previous researchers i.e. 500 to $1200{ }^{\circ} \mathrm{C}$ with the total energy produced from the charcoal is listed in Table 1. According to Seifrtiz (1993) [1] that $\pm 50 \%$ of burned biomass is extracted become charcoal form. Meanwhile, refer to Glaser (2002) [2] average 49.9\% carbon yield which produced from various types of kilns including laboratory furnace. That phenomenon means that approximately of $50 \%$ from total carbon inside of raw material emitted to the air with half-carbonized matter form [2].

Table 1. Product of charcoal carbonization [3]

\begin{tabular}{|l|c|}
\hline Product of carbonization & \% Dry base \\
\hline Charcoal (80\% fixed carbon) & 33 \\
\hline Pyroligneous acid & 35.5 \\
\hline Acetic acid & 0.5 \\
\hline Methanol & 0.2 \\
\hline Soluble tar & 5 \\
\hline
\end{tabular}

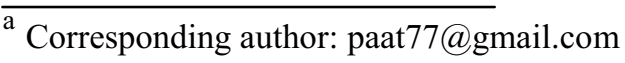

\begin{tabular}{|l|c|}
\hline Water and other & 23.5 \\
\hline Insoluble tar & 6.5 \\
\hline Non condensable gases (HCG) & 25 \\
\hline Hydrogen-0.63\% & 0.16 \\
\hline $\mathrm{CO}-34 \%$ & 8.5 \\
\hline $\mathrm{CO}_{2}-62 \%$ & 15.5 \\
\hline Methane $-2.43 \%$ & 0.61 \\
\hline Ethane $-013 \%$ & 0.03 \\
\hline Others $-0.81 \%$ & 0.2 \\
\hline
\end{tabular}

There are many products resulted from the carbonization process as mentioned in Table 1. It respective to the energy loses and it is improved by increasing charcoal yield and make more efficient palm tree plantation in Malaysia since it very abundant (Figure 1) [4].

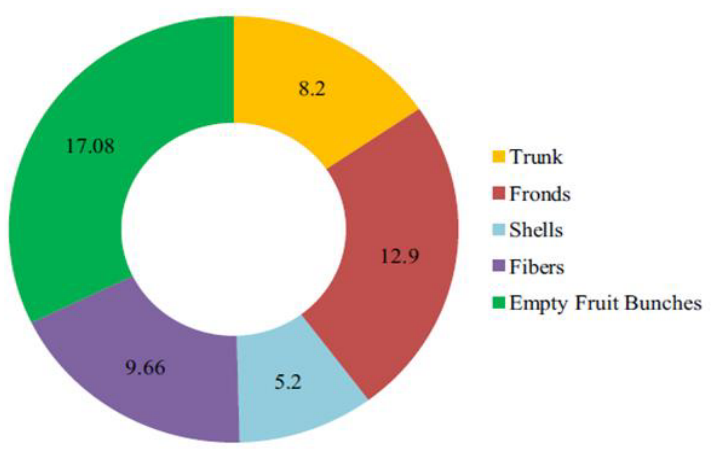

Figure 1 Palm biomass production in Malaysia (million tons per year) [4] 
According to previous researchers [5-11] they have produce activated carbon for air and water filter using laboratory burner and conventional burner which is not based on air flow, thermal flow calculation and not completed by fume handling system. Therefore, the conventional activated carbon is produced by high cost operation and longtime production as well as not environmental friendly. Some limitation of the existing burner that fine activated carbon size is dominated in this production and also high ash volume. Fine activated carbon is only suitable for lab scale and it caused by slower diffusion through particles and high pressure loss across the bed. High ash volume is indicated that the designed burner is not effective to control the temperature inside the burner, it will cause over heated and reduce the properties of the activated carbon. Therefore, this research is aimed to develop new burner for producing activated carbon where designed burner based on charcoal size before and after burned, air circulation, heat circulation and ash volume analysis.

\section{Types and Characteristic of Kilns}

There are several types of kilns which have been investigated by previous researchers. It has unique characteristics for burning and producing charcoal regarding to the time and temperature.

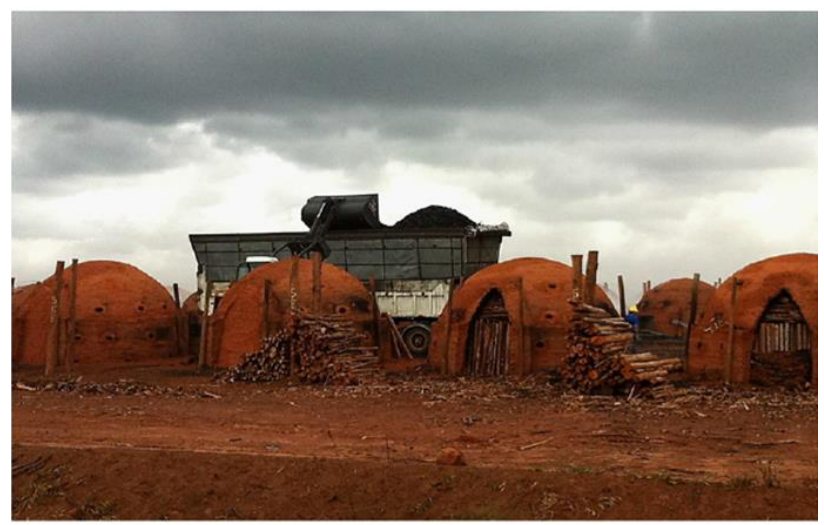

Figure 2 Hot tail kilns

This kiln has maximum diameter, height and charcoal/load of $2.8 \mathrm{~m}, 2.8 \mathrm{~m}$ and $4 \mathrm{~m}^{3}$, respectively. It is producing low yield and it also completed by smoke and tar emission. This kiln need 10 to 12 days for producing charcoal [3].

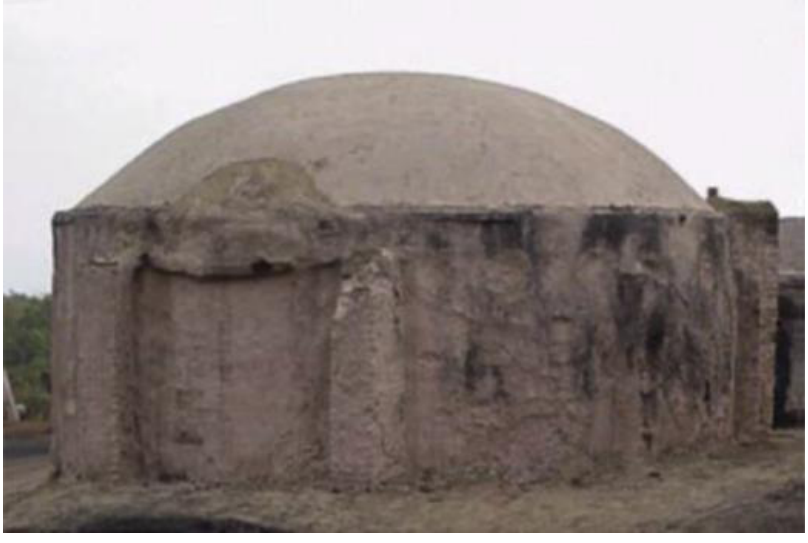

Figure 3 Surface kilns

Surface kiln available for producing $20 \mathrm{~m}^{3}$ charcoal/cycle, diameter of $5 \mathrm{~m}$ and need 10 to 12 days for producing charcoal [3].

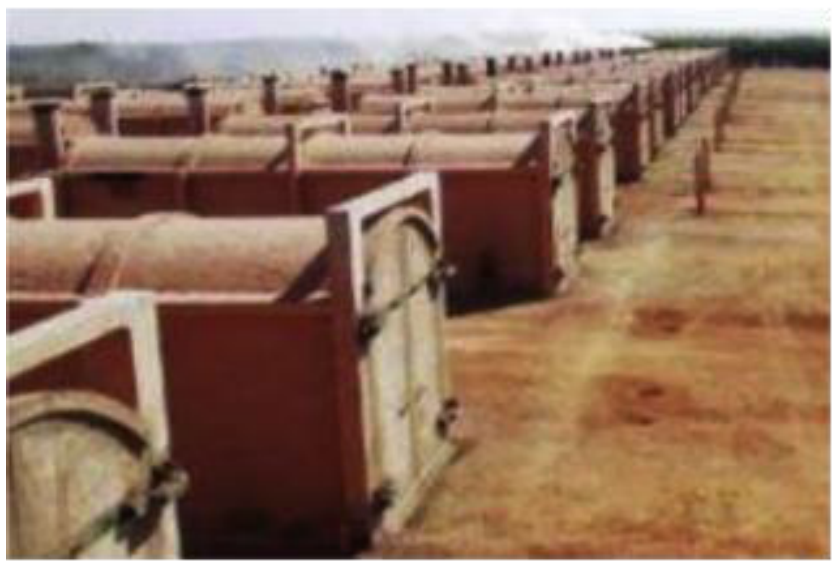

Figure 4 Rectangular kilns

Rectangular kiln has dimension of 13 × 4 × $3.5 \mathrm{~m}(1 \mathrm{x}$ $\mathrm{w} \times \mathrm{h}$ ) with maximum capacity of $200-700 \mathrm{~m}^{3}$ and this kiln need 15 days operation times for producing charcoal [3].

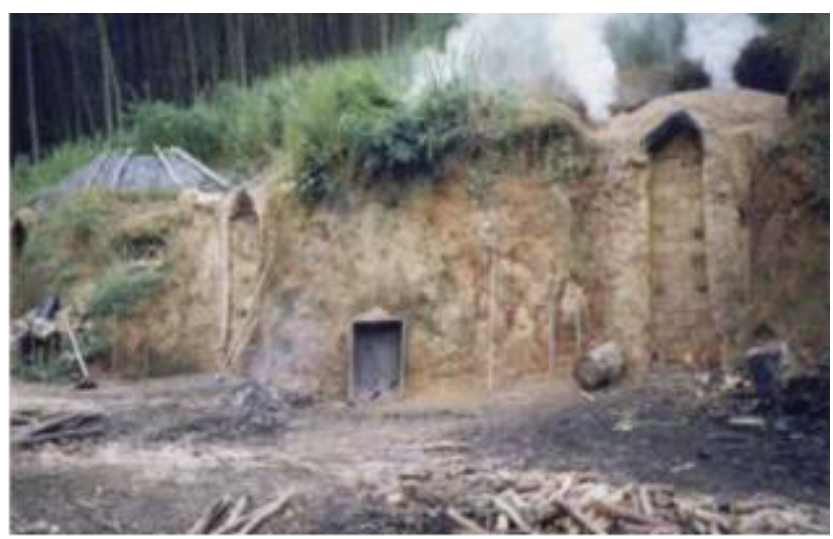

Figure 5 Slope kilns

Work principle of slop kilns is similar with hot tail kilns with low cost and low yield not more than $25 \%$ [3]. 


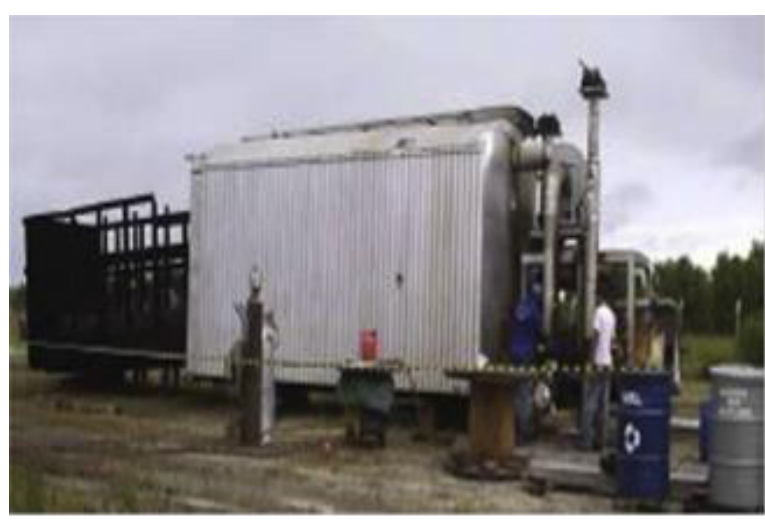

Figure 6 DPC process

This kiln is completed by gas flow system which used as thermal fluid and it need $60 \mathrm{~h}$ for each cycle [3].

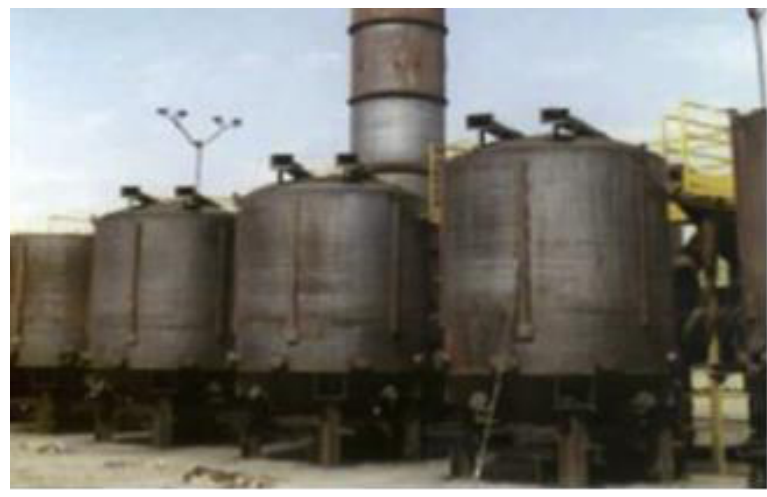

Figure 7 CML France

This kiln available for producing $2500 \mathrm{t} /$ years with low yield of $20-25 \%$. Every cycle, this kilns can prodding at least $2 \mathrm{~m}^{3}$ which need $24 \mathrm{~h}$ for production time [3].

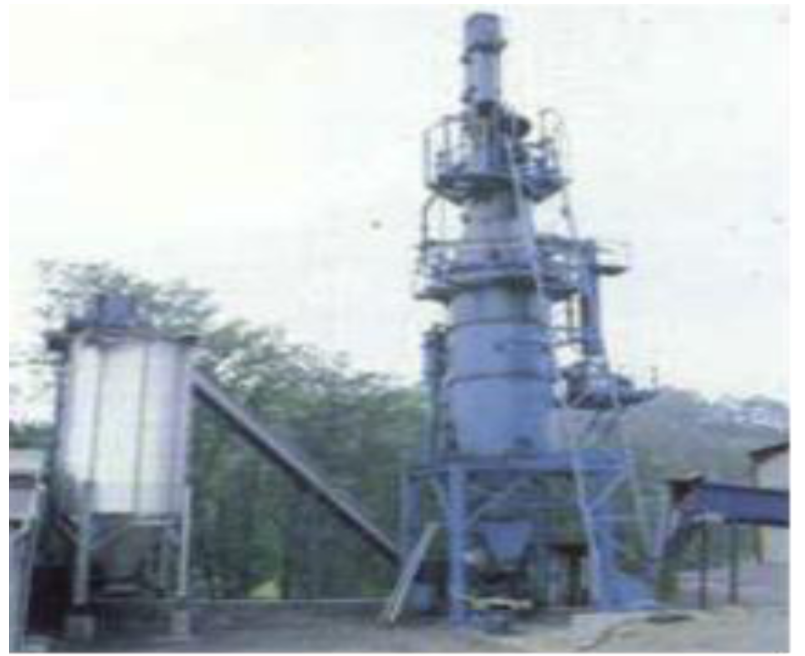

Figure 8 Continuous retort

Continuous retort conduct the burning process by hot gases from combustion system. Raw material at condition approximately of $20 \%$ humidity and feeding material in the top of the kilns while discharging cold charcoal is located at the bottom with tar recovering. This kiln is available for producing charcoal of 2,000 to $10,000 \mathrm{t} /$ year [3].

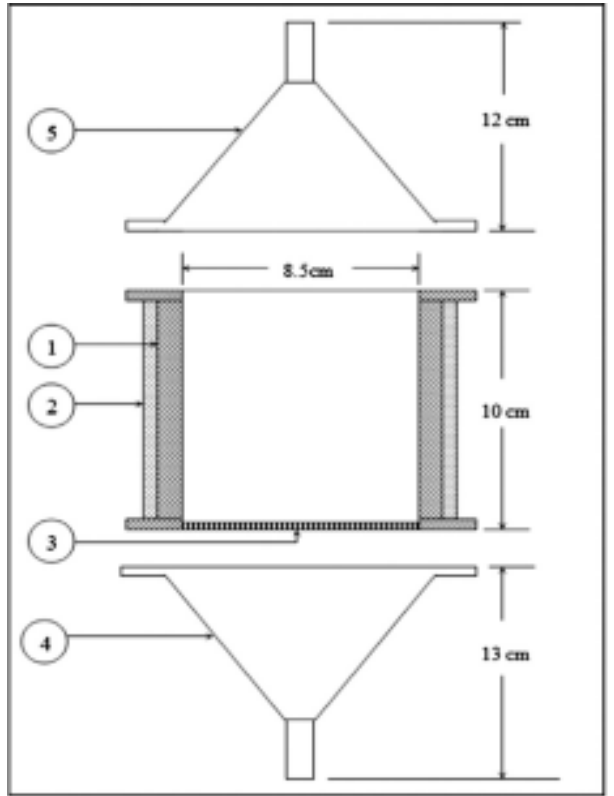

Figure 9 The layout and dimensions of burner housing, inlet chamber and top cover. 1 . Stainless steel body (thickness $=$ $3 \mathrm{~mm}$ ), 2. Silica insulation (thickness $=5 \mathrm{~mm}$ ), 3. Cast iron grill (plat form for porous layers), 4. Inlet chamber (stainless steel, diameter $8.5 \mathrm{~cm}$ ), 5. Top cover (for exhaust gas sampling) [12].

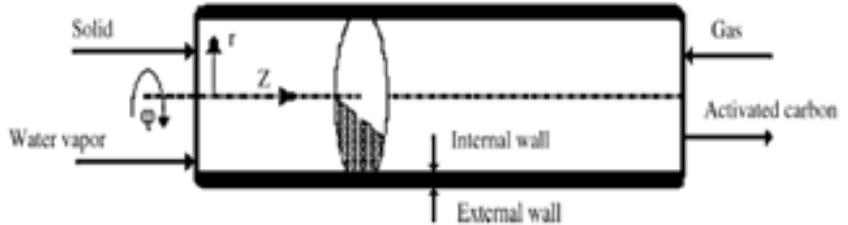

Figure 10 A pilot rotary kiln [13]

Working principle of a pilot rotary kiln is it rotates in longitudinal axis and it operates as heat exchanger. System of this kiln i.e. hot gas is produced by combustion of natural gas which originated from central burner; supply the necessary energy for the activation reaction. In this system, water vapor is injected in concurrent mode as activation agent. The moisture content of raw material approximately of $5-10 \%$ and impurity content of the raw material is negligible. It is supposed that the solid bed moves as a pseudo fluid with axial displacement and without retro-mixing and it rolls or slides in transverse direction as the cylinder rotates [13].

Table 2 Specification of pilot rotary kiln [13]

\begin{tabular}{|l|l|}
\hline Length & $3.7 \mathrm{~m}$ \\
\hline Internal diameter & $0.3 \mathrm{~m}$ \\
\hline External diameter & $0.6 \mathrm{~m}$ \\
\hline Raw material & Solid carbonaceous material \\
\hline Reaction temperature & $800-1000^{\circ} \mathrm{C}$ \\
\hline Rotary kiln pressure & Atmospheric \\
\hline Rotation speed & 1 to $3 \mathrm{rpm}$ \\
\hline Heating medium & Natural gas combustion \\
\hline
\end{tabular}


In real production of $\mathrm{AC}$, the rotary kiln plan was able to convert $2000 \mathrm{~kg} / \mathrm{hr}$ capacity of olive pits into char fated for the production of activated carbon in Italy. The pyrolysis process temperature between $50-750^{\circ} \mathrm{C}$ at fixed biomass with flow rate of $1700 \mathrm{~kg} / \mathrm{hr}$. operating temperature of $300-400{ }^{\circ} \mathrm{C}$ and higher operating temperature is 800 to $900{ }^{\circ} \mathrm{C}$. The length of the kiln is 20 $\mathrm{m}$ and internal diameter is $1.6 \mathrm{~m}$ [14]. Rotary kiln is also used for recycling of waste composite material (thermoset - based polymer composites) collected from the products such as automobiles, wind turbines and aircrafts [15].

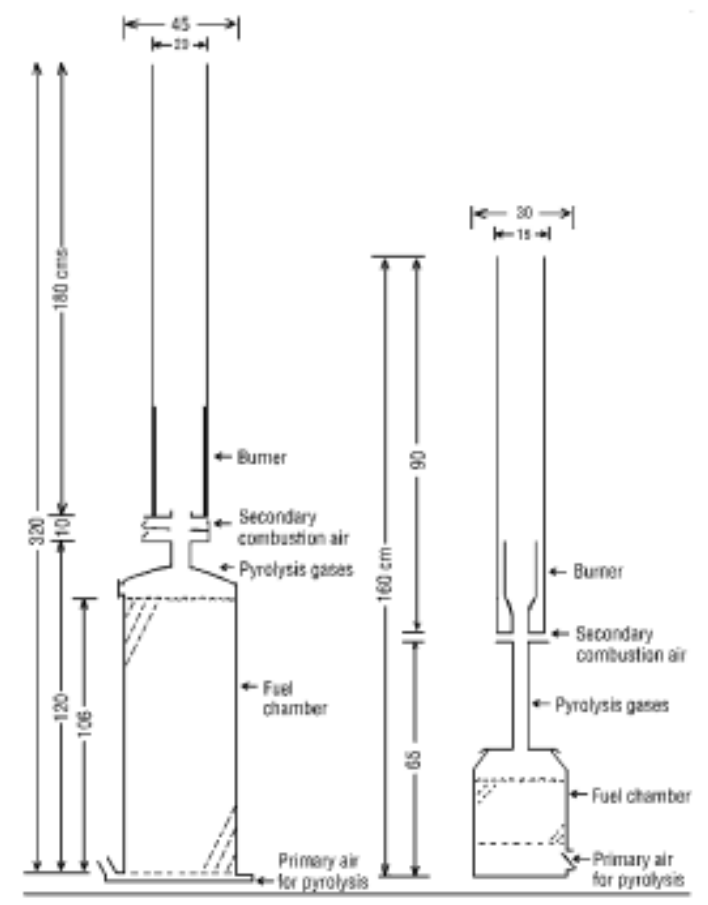

Figure 11 Large pyrolyser/burner on the left and small pyrolyser/burner on the right (individually to scale) [16]

According to Figure 11 that those design have basic operation mode i.e.

1. Fuel chamber is filled with raw material.

2. Pellets are lit on top.

3. Pellets are allowed to burn for a few minutes until pyrolysis has moved down into the fuel and spread over the entire top surface of the fuel.

4. Gas and air mixture is lit in the burner.

5. Flame is sustained until fuel is completely turned to charcoal.

6. Fuel chamber is sealed and allowed to cool.

7. Charcoal is removed.

There are differences between small and large burner regarding to the fuel chamber and the burner. Both burners are ignited by pilot flames up to gas production can support sell-ignition in the combustion chamber. Primary air supply into the bottom of the fuel chamber is left fully open at the beginning. Primary air was not adjusted for large burner and it different with small burner. Small burner need operator to control the primary air to moderate burning gas production while secondary air was adjusted for both of burner. In small burning process, the operator adjust air supply level up to appropriate results is achieved which based on stack gases, visual and auditory characteristics of the flame. Testing process of large burner controlled by plug as the function to stop the air inlet to the fuel chamber prior to reaction zone is reached by fuel column bottom in order to allowing an inspection of reaction zone.

\section{Proposed Kilns}

There are several types of the proposed kilns such as vertical kilns and horizontal kilns. It developed using mild steel hollow, mild steel plate and mild steel angle bar and it fabricated using several equipment such as welding, oxy-cutting, drilling grinding and cutting machine. New burner is completed by several equations regarding to the air and thermal flow analysis.

\section{Volume calculation}

$$
\begin{aligned}
& \text { Air Change / hour }=\frac{C F M x 60}{\text { Cubicfeet }} \\
& C F M=\text { Room Volume } x \frac{\text { Air Change/ hour }}{60}
\end{aligned}
$$

\section{Air flow formula}

$$
\begin{aligned}
& C F M=C_{V} x \sqrt{\Delta P(\text { inches }) \mathrm{H}_{2} \mathrm{O}} \\
& C_{V}=\sqrt[3]{\frac{C F M}{\Delta P(\text { inches }) \mathrm{H}_{2} \mathrm{O}}}
\end{aligned}
$$

Where;

$C F M=$ Duct area sq. ft. $\mathrm{x}$ Velocity

$\Delta P=$ Pressure in - pressure out

\section{Air thermal calculation}

$$
B T U H=M x \text { sp.ht } x \Delta T
$$

Where;

$\mathrm{BTUH}=$ Air thermal

$\mathrm{M}=$ Mass flow rate $(\mathrm{Lbs} . / \mathrm{h})$

Sp.ht $=$ Specific heat $($ BTU/Lb./Degree $)$

Proposed burner is designed with environmentally concern in air pollution. Therefore, it completed by fume handling system. Dimension of vertical kilns is $15 \mathrm{~cm}$ and $120 \mathrm{~cm}$ for diameter and height. It completed by several holes in the bottom side purposed to air circulation and discharge hole for cold charcoal. Meanwhile, horizontal burner is completed by automatic rotating system by motor for every 2 minutes in $45^{\circ}$ rotating. Fume handling also installed into the kilns which operated when fume is going out from the hollow steel and discharged into the water in order to remove 
fumes by mixing into the water. Vertical and horizontal kilns is shown in Figure 12 and 13.

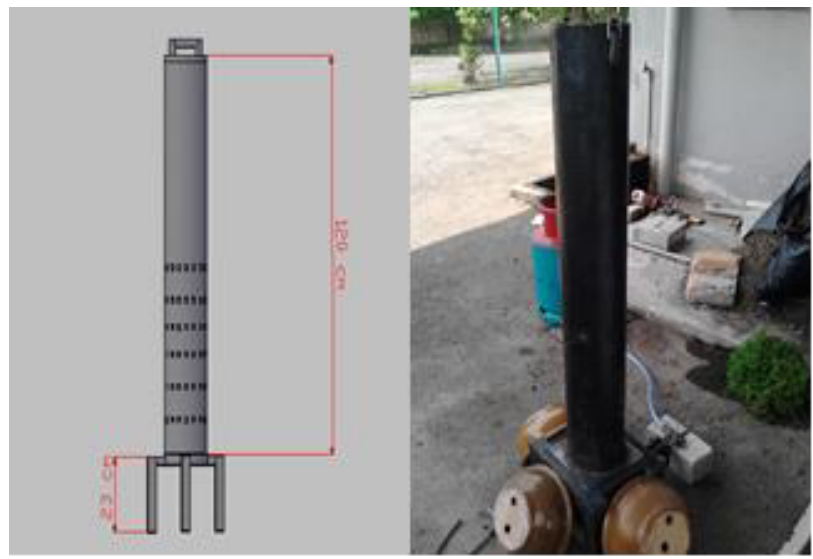

Figure 12 Vertical kilns

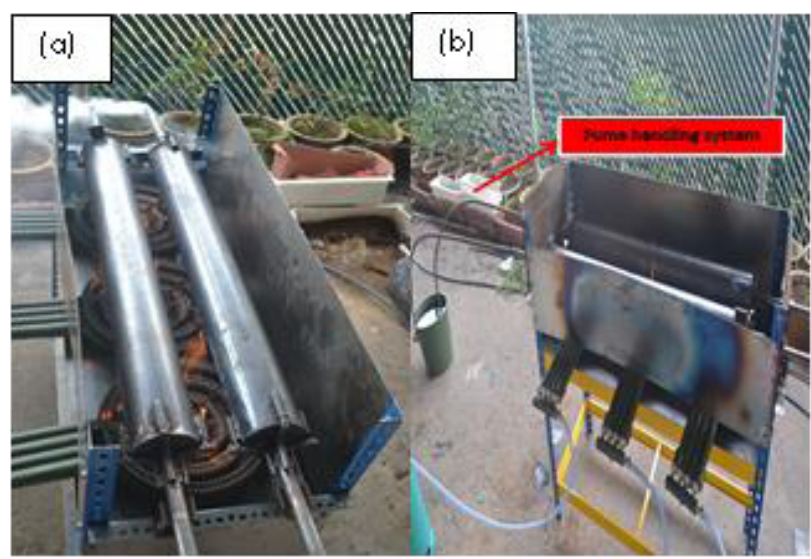

Figure 13 Horizontal kilns (a) without fume handling system and (b) with fume handling system

\section{Expected Result of Palm Shell Charcoal}

Capacity charcoal production of this burner is $20 \mathrm{~kg} /$ cycle and $2 \mathrm{~h} /$ cycle for palm shell charcoal as well as 30 minutes/cycle for coconut shell charcoal. Temperature $300-600{ }^{0} \mathrm{C}$ controlled by gas outlet rotating valve. Palm shell and coconut shell charcoal is shown in Figure 14.

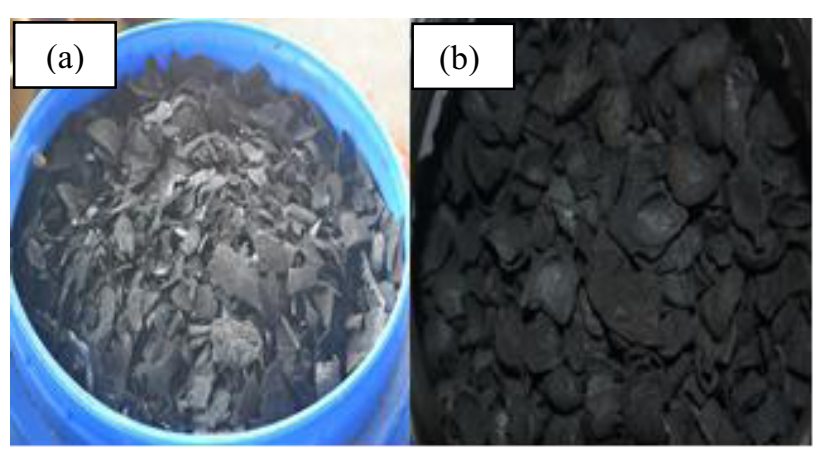

Figure 14 (a) Coconut shell charcoal and (b) Palm shell charcoal
Shorter time of the burning process as compared to existing kilns indicated that this kiln more efficiency regarding in time production. It also effective for handling fume to secure the environment in healthy level. Potential results of this charcoal refer to Rahman et al., (2012) [17] based on the surface area and pore diameter are shown in Figure 15 and Table 3. The charcoal is activated using phosphoric acid with the percentage 10 , 20 and $30 \%$ in order to improve surface area and improve total pore volume. Reaction during carbonization can effect to the pore distribution and rough surface will effect to the lack pores development [17].

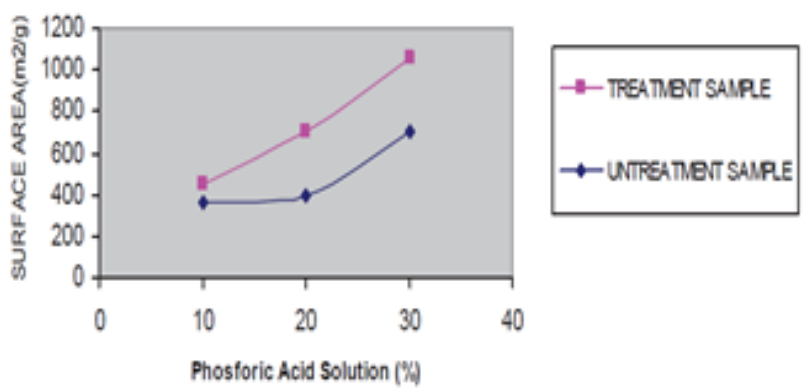

Figure 15 The surface area of treated and untreated activated carbon [17]

Table 3. Effect of untreated, treated activated carbon on pore diameter and pore volume with different phosphoric concentration [17]

\begin{tabular}{|c|c|c|}
\hline $\begin{array}{c}\text { Sample } \\
\text { name }\end{array}$ & $\begin{array}{c}\text { Average pore } \\
\text { diameter }\left(10^{-5} \mathrm{~m}\right)\end{array}$ & $\begin{array}{c}\text { Total pore volume } \\
(\mathrm{cc} / \mathrm{g})\end{array}$ \\
\hline $\mathrm{U} 10$ & $2.137 \mathrm{E}+01$ & $1.961 \mathrm{E}-01$ \\
\hline $\mathrm{U} 20$ & $2.126 \mathrm{E}+01$ & $2.129 \mathrm{E}-01$ \\
\hline U30 & $2.063 \mathrm{E}+01$ & $3.611 \mathrm{E}-01$ \\
\hline T10 & $2.147 \mathrm{E}+01$ & $2.445 \mathrm{E}-01$ \\
\hline T20 & $2.143 \mathrm{E}+01$ & $3.758 \mathrm{E}-01$ \\
\hline T30 & $2.064 \mathrm{E}+01$ & $5.457 \mathrm{E}-01$ \\
\hline
\end{tabular}

Optimum surface area of untreated activated carbon is $700.1 \mathrm{~m}^{2} \mathrm{~g}^{-1}$ while for treated activated carbon is 1058 $\mathrm{m}^{2} \mathrm{~g}^{-1}$. It means that the treatment or activation process may increase the surface area and adsorption capacity of activated carbon.

\section{Conclusion}

Carbonization process for activated carbon production is conducted with new proposed design completed by autorotating and fume handling system. This kiln need shorter carbonization time of 30 minutes for coconut shell charcoal and $2 \mathrm{~h}$ for palm shell charcoal. Meanwhile existing burner/kilns need longer carbonization up to 24 h. Charcoal with shorter carbonization time indicated that it have homogeneity thermal distribution and it can effect to the increment of pore development and higher surface area which led to higher adsorption capacity of produced activated carbon 


\section{Acknowledgement}

The authors would like to thank the Ministry of Higher Education Malaysia and Universiti Tun Hussein Onn Malaysia (UTHM) through the funding supported ICI grant under No Vot. I002 and Centre for Graduate Studies - UTHM.

\section{References}

1. W. Seifrits. Should we store carbon in charcoal. Int. J. Hydrogen Energy, 18, 5: 405-407 (1993).

2. B. Glaser, J. Lehmann and W. Wolfgang Zech. Ameliorating physical and chemical properties of highly weathered soils in the tropics with charcoal - a review. Biol Fertil Soils, 35, 219-230 (2002).

3. O.V. Adriana, S.L. Electo, R.Q. Quelbis, A.V. Ricardo and P.S.S. Thalis. A new technology for the combined production of charcoal and electricity through cogeneration. Biomass and bio energy, 69, 222-240 (2014).

4. S.E. Hosseini, and M. Abdul Wahid. Utilization of palm solid residue as a source of renewable and sustainable energy in Malaysia. Renewable and Sustainable Energy Reviews, 40, 621-632 (2014).

5. T.A. Metts and S.A. Batterman. Effect of VOC loading on the ozone removal efficiency of activated carbon filter. Chemosphere, 62, 34-44 (2006).

6. M.A. Sidheswaran, H. Destaillats, D.P. Sullivan, S. Cohn and W.J. Fisk. Energy efficient indoor VOC air cleaning with activated carbon fiber (ACF) filter. Building and Environment, 47, 357-367 (2012).

7. E. Gallego, F.J. Roca, J.F. Perales and X. Guardino. Experimental evaluation of VOC removal efficiency of a coconut shell activated carbon filter for indoor air quality enhancement. Building and Environment, 67, 14-25 (2013).

8. N.A. Fuadi, A.S. Ibrahim and K.N. Ismail. Review study for activated carbon from palm shell used for treatment of waste water, (2008).

9. S. Wu, B. Dong, T. Qiao and J. Zhang. Effect of a biological activated carbon filter on particle counts. J Zhejiang Univ Sci A. 9, 1,1576-1581 (2008).

10. I. Adedayo, A.O. Inegbenebor and H.I. Boyo. Comparison of the Adsorptive Capacity of Raw Materials in Making Activated Carbon Filter for Purification of Polluted Water for Drinking. ARPN Journal of Science and Technology, 2, 9, ISSN 22257217 (2012).

11. A.A. Ismaiel, M.K. Aroua and R. Yusoff. Palm shell activated carbon impregnated with task-specific ionicliquids as a novel adsorbent for the removal of mercury from contaminated water. Chemical Engineering Journal, 225, 306-314 (2013).

12. M.A. Mujeebu, M.Z. Abdullah and A.A. Mohamad. Development of energy efficient porous medium burners on surface and submerged combustion modes. Energy, 36, 5132-5139 (2011)

13. O.A. Ortiz, S.E. Noriega, C.A. Mengual and N.D. Martínez. Steady State Simulation of a Rotary Kiln for Charcoal Activation. Latin American Applied Research, 33, 51-57 (2003)

14. E. Benanti, C. Freda, V. Lorefice, G. Braccio, and V.K. VinoSharma. Simulation of Olive Pits Pyrolysis in a Rotary Kiln Plant. Thermal Science, 15, 1, 145158 (2011).

15. Y. Yang, R. Boom, B. Brijan Irion, D.J. Heerden, P. Kuiper and W. Hans. Recycling of composite materials. Chem. Eng. Process, (2011).

16. Alex English. Preliminary tests on charcoal making pyrolysis gas burners - high performance combustion with a simple technology. Energy for Sustainable Development, 6, 2. (2002).

17. M.M. Rahman, M. Awang, B.S. Mohosina, W.B. Kamaruzzaman, Wan Nik and C.M.C. Adnan. Waste Palm Shell Converted to High Efficient Activated Carbon by Chemical Activation Method and Its Adsorption Capacity Tested by Water Filtration. APCBEE Procedia, 1, 293 - 298 (2012). 